\title{
Accounting for Population Ageing in Tax Microsimulation Modelling by Survey Reweighting *
}

\author{
Lixin Cai, John Creedy and Guyonne Kalb \\ Melbourne Institute of Applied Economic and Social Research \\ The University of Melbourne
}

Melbourne Institute Working Paper No. 26/04

ISSN 1328-4991 (Print)

ISSN 1447-5863 (Online)

ISBN 0734031688

September 2004

\begin{abstract}
* We should like to thank the Department of Family and Community Services for funding this research. The views expressed in this paper are those of the authors and do not represent the views of the Minister for Family and Community Services, the Department of Family and Community Services or the Commonwealth Government.
\end{abstract}

Melbourne Institute of Applied Economic and Social Research

The University of Melbourne

Victoria 3010 Australia

Telephone (03) 83442100

Fax (03) 83442111

Email melb-inst@unimelb.edu.au

WWW Address http://www.melbourneinstitute.com 


\begin{abstract}
This paper investigates the use of sample reweighting in a behavioural tax microsimulation model, to examine the implications for government taxes and expenditure of population ageing in Australia. First, a calibration approach to sample reweighting is described, producing new weights which achieve specified population totals for selected variables, subject to the constraint that there are minimal adjustments to the weights. Second, the performance of the Australian Bureau of Statistics' (ABS) weights provided with the 2001 Survey of Income and Housing Cost (SIHC) was examined and it was found that reweighting does not improve the simulation outcomes for the 2001 situation, so the original ABS weights were retained for 2001. Third, the implications of changes in the age distribution of the population were examined, based on population projections to 2050. A 'pure' change in the age distribution was examined by keeping the aggregate population size fixed and changing only the relative frequencies in different age-gender groups. Finally, the effects of a policy change to benefit taper rates in Australia were compared for 2001 and 2050 population weights. It is suggested that this type of exercise provides an insight into the implications of changes in the population on government income tax revenue and social security expenditure, indicating likely pressures for policy changes.
\end{abstract}




\section{Introduction}

The aim of this paper is to investigate the use of sample reweighting, with a behavioural tax microsimulation model, to examine the implications for government taxes and expenditure of population ageing in Australia. Tax microsimulation models are based on large-scale cross-sectional surveys containing substantial information about the characteristics of individuals and households. Each household has a sample weight provided by the statistical agency responsible for collecting the data, and these weights are used to 'gross up' from the sample in order to obtain estimates of population values. This applies to aggregates such as income taxation, the number of recipients of a particular social transfer or the number of people in a particular demographic group. In addition, the weights are used in the estimation of measures of population inequality and poverty.

The possibility therefore arises of adjusting the sample weights to reflect anticipated changes in the population age structure. Revised weights can then be used to estimate implications for labour force participation and expenditures, on the assumption that other characteristics remain unchanged. Other possibilities could also be considered at the same time, including for example the potential effects of real wage growth or of changes to the tax and benefit regime. Such changes are of course likely to arise partly as a response to the pressures of population ageing, so it is useful to be able to examine the precise nature of those pressures.

Such an approach contrasts with a popular method of examining population ageing, which combines population projections with age-specific per capita expenditures on a range of benefits in order to obtain projected social expenditures. These are typically combined with GDP projections based on age-specific labour force participation and unemployment ratios, along with productivity growth assumptions. While accounting frameworks of this type have proved useful, they necessarily lack the kind of policy modelling, detail and heterogeneity available in microsimulation models. ${ }^{1}$

The microsimulation model used here is the Melbourne Institute Tax and Transfer Simulator (MITTS). This is a behavioural tax microsimulation model allowing detailed examination of the potential effects on government direct tax revenue and

\footnotetext{
${ }^{1}$ On this type of modelling, see Alvarado and Creedy (1998).
} 
expenditure of policy reforms to the tax and transfer system. ${ }^{2}$ The database is the Australian Survey of Income and Housing Costs (SIHC), a large-scale cross-sectional survey of about seven thousand households, with each household having a sample weight provided by the Australian Bureau of Statistics (ABS).

This paper therefore begins by describing a calibration approach to sample reweighting which achieves specified population totals for selected variables, subject to the constraint that there are minimal adjustments to the weights. A formal statement of the problem of obtaining 'minimum distance' weights and a general approach to the solution are described in Section 2. Section 3 applies the approach to the SIHC, and considers whether - before examining population ageing - the SIHC needs to be reweighted for tax simulation purposes. Reweighting to allow for population ageing is examined in Section 4, which makes use of ABS population projections. The analysis abstracts from changes in population size and concentrates purely on changes in the age structure. Section 5 reports simulation results of a tax policy change with the revised weights, reflecting the aged population structure. Brief conclusions are in Section 6.

\section{The Calibration Approach}

This section discusses methods of calibration. Subsection 2.1 provides a general statement of the problem of minimising the overall distance between two sets of weights, subject to a set of calibration conditions. Subsection 2.2 examines a class of distance functions giving rise to a convenient structure. An iterative solution procedure is presented in subsection 2.3.

\subsection{Statement of the Problem}

For each of $K$ individuals in a sample survey, information is available about $J$ variables; these are placed in the vector:

$$
x_{k}=\left[\begin{array}{c}
x_{k, 1} \\
\cdot \\
\cdot \\
\cdot \\
x_{k, J}
\end{array}\right]
$$

\footnotetext{
${ }^{2}$ For further details of the MITTS model see Creedy et al. (2002).
} 
For present purposes these vectors contain only the variables of interest for the calibration exercise. Most elements of $x_{k}$ are likely to be $0 / 1$ variables. For example $x_{k, j}=1$ if the $k^{\text {th }}$ individual is in a particular age group, and zero otherwise. The sum $\sum_{k=1}^{K} x_{k, j}$ therefore gives the number of individuals in the sample, who are in the age group.

The sample design weights, provided by the statistical agency responsible for data collection are $s_{k}$ for $k=1, \ldots, K$. These weights can be used to produce estimated population totals, $\hat{t}_{x \mid s}$, based on the sample, given by the $J$-element vector:

$$
\hat{t}_{x \mid s}=\sum_{k=1}^{K} s_{k} x_{k}
$$

The calibration approach can be stated as follows. Suppose that other data sources, for example census or social security administrative data, provide information about 'true' population totals, $t_{x}$. The problem is to compute new weights, $w_{k}$, for $k=1, \ldots, K$ which are as close as possible to the design weights, $s_{k}$, while satisfying the set of $J$ calibration equations:

$$
t_{x}=\sum_{k=1}^{K} w_{k} x_{k}
$$

It is thus necessary to specify a criterion by which to judge the closeness of the two sets of weights. In general, denote the distance between $w_{k}$ and $s_{k}$ as $G\left(w_{k}, s_{k}\right)$. The aggregate distance between the design and calibrated weights is thus: ${ }^{3}$

$$
D=\sum_{k=1}^{K} G\left(w_{k}, s_{k}\right)
$$

The problem is therefore to minimise (4) subject to (3), for which the Lagrangean is:

$$
L=\sum_{k=1}^{K} G\left(w_{k}, s_{k}\right)+\sum_{j=1}^{J} \lambda_{j}\left(t_{x, j}-\sum_{k=1}^{K} w_{k} x_{k, j}\right)
$$

where $\lambda_{j}$ for $j=1, \ldots, J$ are the Lagrange multipliers.

\footnotetext{
3 Some authors, such as Folsom and Singh (2000) write the distance to be minimised as $\sum_{k=1}^{K} s_{k} G\left(w_{k}, s_{k}\right)$, but the present paper follows Deville and Särndal (1992).
} 


\subsection{A Class of Distance Functions}

Suppose that $G\left(w_{k}, s_{k}\right)$ is such that the differential with respect to $w_{k}$ can be expressed as a function of $w_{k} / s_{k}$, so that:

$$
\frac{\partial G\left(w_{k}, s_{k}\right)}{\partial w_{k}}=g\left(\frac{w_{k}}{s_{k}}\right)
$$

The $K$ first-order conditions for minimisation can therefore be written as:

$$
g\left(\frac{w_{k}}{s_{k}}\right)=x_{k}^{\prime} \lambda
$$

Write the inverse function of $g$ as $g^{-1}$, so that if $g\left(w_{k} / s_{k}\right)=u$, say, then $w_{k} / s_{k}=g^{-1}(u)$. From (7) the $k$ values of $w_{k}$ are expressed as:

$$
w_{k}=s_{k} g^{-1}\left(x_{k}^{\prime} \lambda\right)
$$

If the inverse function, $g^{-1}$, can be obtained explicitly, equation (8) can be used to compute the calibrated weights, given a solution for the vector, $\lambda$.

The Lagrange multipliers can be obtained by post-multiplying (8) by $x_{k}$, summing over all $k=1, \ldots, K$ and using the calibration equations, so that:

$$
t_{x}=\sum_{k=1}^{K} w_{k} x_{k}=\sum_{k=1}^{K} s_{k} g^{-1}\left(x_{k}^{\prime} \lambda\right) x_{k}
$$

Finally, subtracting $\hat{t}_{x \mid s}=\sum_{k=1}^{K} s_{k} x_{k}$ from both sides of (9) gives the nonlinear equations:

$$
t_{x}-\hat{t}_{x \mid s}=\sum_{k=1}^{K} s_{k}\left\{g^{-1}\left(x_{k}^{\prime} \lambda\right)-1\right\} x_{k}
$$

where $s_{k}\left\{g^{-1}\left(x_{k}^{\prime} \lambda\right)-1\right\}$ is a scalar and the left hand side is a known vector. An iterative procedure to solve these equations is given in Appendix A.

\subsection{The Deville and Särndal Distance Function}

The solution procedure requires only an explicit form for the inverse function $g^{-1}(u)$, from which its derivative can be obtained. Hence, it is not necessary to start 
from a specification of $G(w, s) \cdot{ }^{4}$ Deville and Särndal (1992) suggested the use of an

inverse function $g^{-1}(u)$ of the form: ${ }^{5}$

$$
g^{-1}(u)=\frac{r_{L}\left(r_{U}-1\right)+r_{U}\left(1-r_{L}\right) \exp \alpha u}{\left(r_{U}-1\right)+\left(1-r_{L}\right) \exp \alpha u}
$$

where $r_{L}$ and $r_{U}$ are and:

$$
\alpha=\frac{r_{U}-r_{L}}{\left(1-r_{L}\right)\left(r_{U}-1\right)}
$$

Thus $g^{-1}(-\infty)=r_{L}$ and $g^{-1}(\infty)=r_{U}$, so that the limits of $w / s$ are $r_{L}$ and $r_{U}$. Hence the new weights are kept within the range, $r_{L} s_{k}<w_{k}<r_{U} s_{k}$, without the need to make checks during computation. ${ }^{6}$

\section{The Survey of Income and Housing Costs (SIHC)}

This section checks the performance of the ABS weights provided with the SIHC against an extensive set of calibration conditions, and reports revised weights and MITTS totals. The most recent data set available is for 2001, which is used here. The calibration conditions include demographic variables, such as age, family composition, unemployment by age and income support recipiency. For the first three variables, population information is taken from census data (ABS, 2002), while information on the last variable is obtained from administrative data on income support payments.

Details of the calibration conditions are given in tables presented in Appendix B. A comparison between SIHC and census numbers on the age distribution of males and

4 Deville and Särndal (1992) discuss the use of a normalisation whereby $g^{-1}(0)$ is set to some specified value, but this is not necessary for the approach.

5 Singh and Mohl (1996), in reviewing alternative calibration estimators, refer to this 'inverse logit-type transformation' as a Generalised Modified Discrimination Information method. Folsom and Singh (2000) propose a variation on this, which they call a 'generalised exponential model', in which the limits are allowed to be unit-specific. In practice they suggest the use of three sets of bounds for low, medium and high initial weights.

${ }^{6}$ In implementation, the limits are not fixed. They are adjusted to make the range as small as possible, conditional on a solution being found. 
females reveals that the SIHC appears to have too many people in the lower age groups and too few in the higher age groups, particularly in the highest age group for women. ${ }^{7}$

With regard to family composition, except for the group of sole parents with dependent and non-dependent children, all groups appear to be over-represented in the SIHC. ${ }^{8}$ Furthermore, the ABS weights understate the number of unemployed men in all but the 15-19 and 35-44 age groups. In contrast, the ABS overstates the number of unemployed women in all but the 20-34 age groups. The numbers of income support recipients are taken directly from the observed values in SIHC, according to selfreported responses. There are both under- and overestimates of particular subgroups.

The iterative approach described in Section 2 and Appendix A above was applied using the calibration conditions listed in Appendix B. Lower and upper bounds of 0.68 and 1.87 were obtained after experimentation to find the smallest range. Figure 1 presents the distribution of the ratio of the new weight to the ABS weight. Relatively few people have a new weight that is more than 1.4 times as large as the ABS weight. Around 50 per cent of all observations are reweighted by a factor between 0.85 and 1.20 .

Figure 1 Ratio of new weight to ABS weight

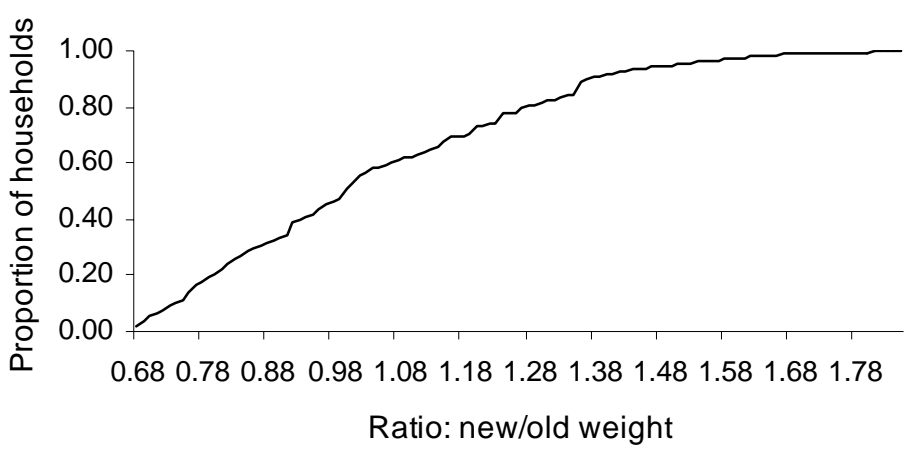

Before considering the performance of MITTS with these new weights, it is useful to compare a few summary measures resulting from calculations using the old and the new weights. First, consider the simulated number of income support recipients based on the two sets of weights, shown in Table 1. The weighting has had little effect on most types of income support recipients. The two main exceptions are disability

\footnotetext{
${ }^{7}$ This is probably caused by the fact that the SIHC excludes people in institutions or people living in remote areas, whereas these groups are included in the Census. An alternative reweighting could be based on total numbers from the Census excluding these groups if possible.

${ }^{8}$ The number of families in the group "other types of family" is omitted from the calibration conditions to avoid singularities
} 
support pensioners, which show an improvement, and age pensioners, where the difference between actual and simulated numbers becomes bigger. The latter is caused by the reweighting on age, putting additional weight on the older age groups. The MITTS model overestimates the proportion of older persons eligible for age pension as a result of the lack of information on assets held by households. People over 60 are amongst those most likely to have built up assets in the form of superannuation or other investments. $^{9}$

Table 1 Actual and simulated numbers $(\times 1000)$ of income support recipients

\begin{tabular}{lrrrrr}
\hline & $\begin{array}{r}\text { Actual } \\
\text { from } \\
\text { FaCS }^{(1)} \\
(1)\end{array}$ & $\begin{array}{r}\text { Simulated } \\
\text { using ABS } \\
\text { weights } \\
(2)\end{array}$ & $\begin{array}{r}\text { Simulated } \\
\text { using new } \\
\text { weights } \\
(3)\end{array}$ & $\begin{array}{r}\text { Difference } \\
\text { between } \\
(1) \text { and (2) }\end{array}$ & $\begin{array}{r}\text { Difference } \\
\text { between } \\
(1) \text { and (3) }\end{array}$ \\
\hline Parenting Payment (single \& & & & & & \\
couple) & 639 & 674 & 602 & -35 & 37 \\
Sickness Allowance & 11 & 21 & 22 & -10 & -11 \\
Widow's Allowance & 36 & 1 & 0 & 35 & 36 \\
AUSTUDY/ABSTUDY & 42 & 135 & 150 & -93 & -108 \\
NewStart Allowance & 541 & 660 & 690 & -119 & -149 \\
Mature Age Allowance & 39 & 47 & 47 & -8 & -8 \\
Youth Allowance & 393 & 674 & 671 & -281 & -278 \\
Special Benefit & 12 & 232 & 246 & -220 & -234 \\
Partner Allowance & 90 & 215 & 212 & -125 & -122 \\
Age Pension & 1,786 & 1,935 & 2,094 & -149 & -308 \\
Disability Support Pension & 624 & 575 & 615 & 49 & 9 \\
Wife's Pension & 78 & 101 & 93 & -23 & -15 \\
Widow B Pension & 9 & 41 & 38 & -32 & -29 \\
Carer's Payment & 57 & 33 & 33 & 24 & 24 \\
Total & 4,357 & 5,344 & 5,513 & -987 & $-1,156$ \\
\hline
\end{tabular}

(1) Source: FaCS (2003).

The aggregate expenditures for a range of benefits produced directly by the SIHC for the old and new weights may be compared; that is, the actual benefits reported as being received by individuals in SIHC are used. Comparisons are shown in Table 2 which reports estimated expenditure obtained directly from SIHC when aggregated using the ABS weights and the revised weights. There seems to be a slight overall improvement resulting from using the new weights. However, when examining particular payment types separately, for some types the amount is much further from the

\footnotetext{
${ }^{9}$ Some alternative approaches are reported in Cai, Creedy and Kalb (2004). For example, observed benefit receipt was used as a requirement for taking up of age pension, and people with eligibility for benefits under \$10 per week are assumed not to take up these benefits. Using observed eligibility for age pension instead of assets (which are not observed) improves the simulation of the number of recipients, but does not improve the estimated expenditure.
} 
actual amount than before the reweighting, whereas for other types an improvement is evident.

Table 2 Actual and estimated expenditure on income support

\begin{tabular}{|c|c|c|c|c|c|}
\hline & $\begin{array}{r}\text { Actual } \\
\text { from } \\
\mathrm{FaCS}^{(1)} \\
(\$ \mathrm{~m})(1)\end{array}$ & $\begin{array}{r}\text { SIHC using } \\
\text { ABS } \\
\text { weights } \\
(\$ \mathrm{~m})(2)\end{array}$ & $\begin{array}{r}\text { SIHC using } \\
\text { new } \\
\text { weights } \\
(\$ \mathrm{~m})(3)\end{array}$ & $\begin{array}{r}\text { Diff. } \\
\text { between } \\
(1) \text { and } \\
(2)\end{array}$ & $\begin{array}{r}\text { Diff. } \\
\text { between } \\
(1) \text { and } \\
(3)\end{array}$ \\
\hline \multicolumn{6}{|l|}{ Parenting Payment (single } \\
\hline \& couple) & $5,327.0$ & $4,911.3$ & $4,303.7$ & 415.7 & $1,023.2$ \\
\hline Sickness Allowance & 95.9 & 212.7 & 223.0 & -116.8 & -127.1 \\
\hline Widow's Allowance & 330.2 & 402.5 & 369.1 & -72.3 & -39.0 \\
\hline AUSTUDY/ABSTUDY & 255.6 & $\mathrm{n} / \mathrm{a}^{(2)}$ & $\mathrm{n} / \mathrm{a}$ & & \\
\hline NewStart Allowance & $4,918.3$ & $3,466.2$ & $3,858.9$ & $1,452.1$ & $1,059.5$ \\
\hline Mature Age Allowance & 353.1 & 329.1 & 304.9 & 24.1 & 48.2 \\
\hline Youth Allowance & $2,121.6$ & $1,446.2$ & $1,521.1$ & 675.4 & 600.5 \\
\hline Special Benefit & 113.8 & 150.5 & 164.9 & -36.6 & -51.1 \\
\hline Partner Allowance & 717.1 & 605.2 & 668.2 & 111.9 & 48.9 \\
\hline Age Pension & $15,571.8$ & $14,233.9$ & $15,681.1$ & 1,337.9 & -109.4 \\
\hline Disability Support Pension & $5,837.4$ & $5,182.7$ & $5,656.3$ & 654.7 & 181.1 \\
\hline Wife's Pension & 680.0 & 491.7 & 445.0 & 188.3 & 235.0 \\
\hline Widow B Pension & 75.3 & $\mathrm{n} / \mathrm{a}^{(2)}$ & $\mathrm{n} / \mathrm{a}$ & & \\
\hline Carer's Payment & 478.3 & 605.2 & 582.3 & -127.0 & -104.0 \\
\hline Total & $36,875.4$ & $32,037.2$ & $33,778.5$ & $4,507.4$ & $2,765.8$ \\
\hline
\end{tabular}

(1) Source: FaCS (2001).

(2) AUSTUDY and Widow B Pension cannot be identified from SIHC data.

Finally, the performance of MITTS with regard to expenditures using the different sets of weights is illustrated in Table 3. Table 3 is similar to Table 2 but compares the simulated expenditure based on the reweighted SIHC data with the simulated expenditure based on the original SIHC data.

Comparing Tables 2 and 3, it can be seen that the difference between the actual expenditure and the simulated expenditure is smaller than the difference between the actual expenditure and the expenditure observed from SIHC. However, the reweighting does not improve the simulated expenditure. In fact, the difference between actual and simulated expenditure for 2001 is quite small with the initial weights, although there are a few exceptions. Regarding the Widow's Allowance and the Widow B Pension it seems that the two payments cannot be separated as they should, but in aggregate the simulated amount paid on these is quite close to the simulated amount. Similarly, adding the NewStart Allowance and the Partner Allowance seems to smooth out differences between actual and simulated amounts.

There remain AUSTUDY and Special Benefit, both of which are overestimated in MITTS. The Special Benefit has strict requirements which cannot easily be tested in 
MITTS because not all necessary information is available in SIHC. For AUSTUDY, the recipient needs to undertake a qualifying study and again this information is not available in SIHC. ${ }^{10}$ From the lack of improvement - indeed deterioration - in simulated expenditures after reweighting, the conclusion is drawn that reweighting the base data for simulations of policy in the current time period cannot be recommended.

Table 3 Actual and simulated expenditure on income support

\begin{tabular}{lrrrrr}
\hline \multicolumn{5}{c}{ Simulated using } \\
& $\begin{array}{r}\text { Actual } \\
\text { from } \\
\mathrm{FCS}^{(1)}\end{array}$ & $\begin{array}{r}\text { ABS } \\
\text { weights } \\
(\$ \mathrm{Mm})(2)\end{array}$ & $\begin{array}{r}\text { new } \\
\text { weights } \\
(\$ \mathrm{~m})(3)\end{array}$ & $\begin{array}{r}\text { Diff. } \\
\text { between } \\
(1) \text { and } \\
(\mathbf{m})\end{array}$ & $\begin{array}{r}\text { Diff. } \\
\text { between } \\
(1) \text { and } \\
(3)\end{array}$ \\
\hline Parenting Payment (single & & & & & \\
and couple) & $5,327.0$ & $5,037.5$ & $4,454.7$ & 289.5 & 872.3 \\
Sickness Allowance & 95.9 & 181.7 & 193.6 & -85.8 & -97.7 \\
Widow's Allowance & 330.2 & 4.9 & 3.5 & 325.3 & 326.7 \\
AUSTUDY/ABSTUDY & 255.6 & 947.1 & $1,000.6$ & -691.5 & -745.0 \\
NewStart Allowance & $4,918.3$ & $4,268.1$ & $4,562.9$ & 650.2 & 355.4 \\
Mature Age Allowance & 353.1 & 221.2 & 244.3 & 131.9 & 108.8 \\
Youth Allowance & $2,121.6$ & $2,475.7$ & $2,463.7$ & -354.1 & -342.1 \\
Special Benefit & 113.8 & $1,910.2$ & $2,036.1$ & $-1,796.4$ & $-1,922.3$ \\
Partner Allowance & 717.1 & $1,493.2$ & $1,492.4$ & -776.1 & -775.3 \\
Age Pension & $15,571.8$ & $15,865.0$ & $17,401.7$ & -293.2 & $-1,829.9$ \\
Disability Support Pension & $5,837.4$ & $5,133.8$ & $5,610.6$ & 703.6 & 226.8 \\
Wife's Pension & 680.0 & 792.9 & 729.9 & -112.9 & -49.9 \\
Widow B Pension & 75.3 & 398.2 & 360.5 & -322.9 & -285.2 \\
Carer's Payment & 478.3 & 274.1 & 272.4 & 204.2 & 205.9 \\
\hline Total & $36,875.4$ & $39,003.6$ & $40,826.9$ & $-2,128.2$ & $-3,951.5$ \\
\hline
\end{tabular}

(1) Source: FaCS (2001).

\section{Population ageing}

The previous section showed that reweighting the base sample for the current time period is unlikely to improve the outcome of simulations. This section explores the use of MITTS in combination with reweighting to examine the implications of population ageing. Projected population distributions by age and gender for 2050 from the ABS (2003) are used to reweight the population in 2000/01 SIHC. However, to avoid the effects of changes in population size, it is assumed that the total population size does

\footnotetext{
${ }^{10}$ A wide range of alternatives, including the imposition of take-up conditions and basing the calibration on numbers calculated by MITTS, based on entitlement according to reported characteristics, are discussed in Cai, Creedy and Kalb (2004).
} 
not change: only the proportion in each subgroup is used. The calibration conditions in the reweighting exercise then consist of the reallocated population totals by age and gender.

ABS (2003) presents three series of projections for 2050. Series B results in a medium-sized stable population, based on a fertility rate of 1.6 babies per woman, a net overseas migration of 100,000 persons and a life expectancy at birth of 84.2 for men and 87.7 for women. Series A presents a larger population based on a fertility rate of 1.8 babies per woman, a net overseas migration of 125,000 persons and a life expectancy at birth of 92.2 for men and 95.0 for women. Series C presents a declining population size based on a fertility rate of 1.4 babies per woman, a net overseas migration of 70,000 persons and a life expectancy at birth of 84.2 for men and 87.7 for women.

The distributions across age-gender groups are also different for the three scenarios. Figure 2 presents the age-gender distribution in the three population projection series. It shows that the proportion of young individuals is lowest in series $\mathrm{C}$ and highest in series A. The proportion of older individuals is highest for series $\mathrm{C}$ and lowest for series B. ${ }^{11}$ Finally, series $\mathrm{B}$ has the largest proportion of the population in the working age category. ${ }^{12}$ Therefore, series $\mathrm{A}, \mathrm{B}$ and $\mathrm{C}$ are referred to in this paper respectively as the young, medium and old population projections.

\section{Figure 2 Gender and age distributions of current and projected populations}

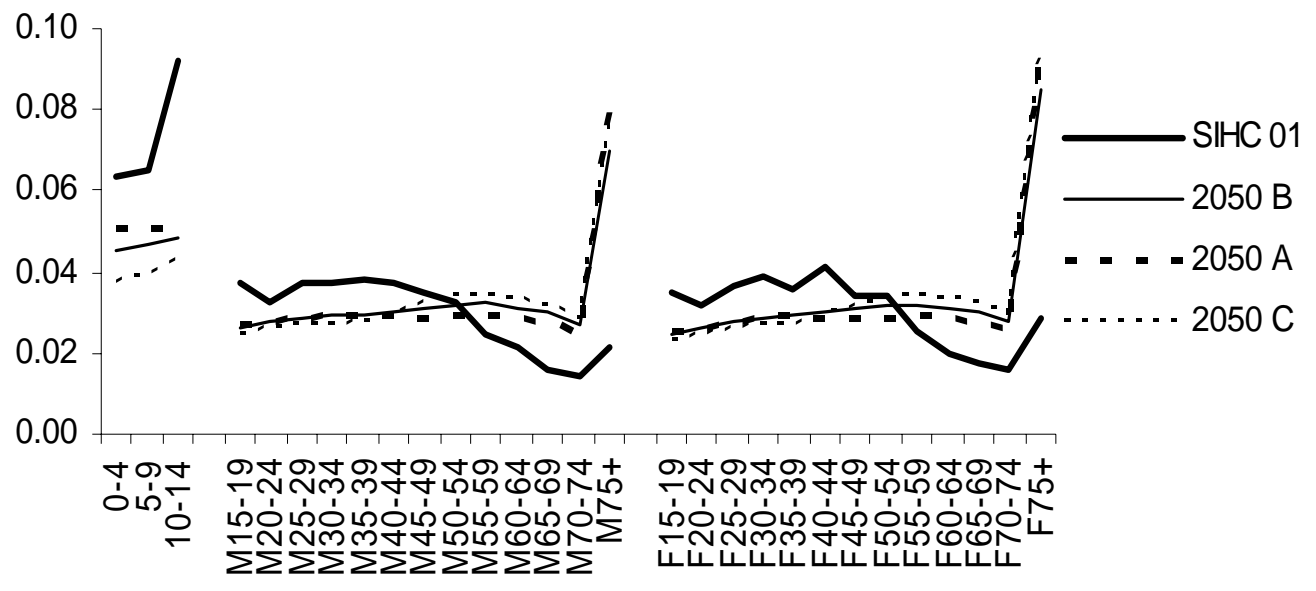

\footnotetext{
11 The proportion of the population aged 65 and over for series A, B and C is 28.03, 26.94 and 29.45 per cent, respectively.

12 The proportion of the working age population for series A, B and C is 56.71, 59.00 and 58.49 per cent, respectively.
} 
In all three projections, the proportion of older persons has increased relative to the younger age groups. Assuming that people's behaviour remains similar to current behaviour of comparable individuals, the effect on expenditure and revenue can be simulated. Under the same assumption, behavioural responses to policy changes can be simulated as well. The reweighting procedure is discussed in Section 4.1.

\subsection{Reweighting Procedure}

As mentioned above, the calibration conditions are constructed from the population projections for 2050 by the ABS (2003). Figure 2 also presents the age-gender distribution of the 2000-2001 SIHC sample. ${ }^{13}$ From the graph, it is clear that there is a decrease in the younger age groups (up to about 54 years) and an increase in the proportion of older Australians. The patterns are similar for men and women. Only the proportion of older women is slightly higher than the proportion of older men for all current and projected populations. This is no surprise, given the longer life expectancy of women.

The proportions presented in Figure 2 are used to calculate revised weights based on the original ABS weights. Given the low impact of the reweighting discussed in the previous section, the reweighting here is based only on the updated age and gender distribution. Figure 3 presents the distribution of the ratio of the new weights resulting from this procedure relative to the ABS weights.

\section{Figure 3 Ratio of new weight for 2050 population structures and ABS weight}

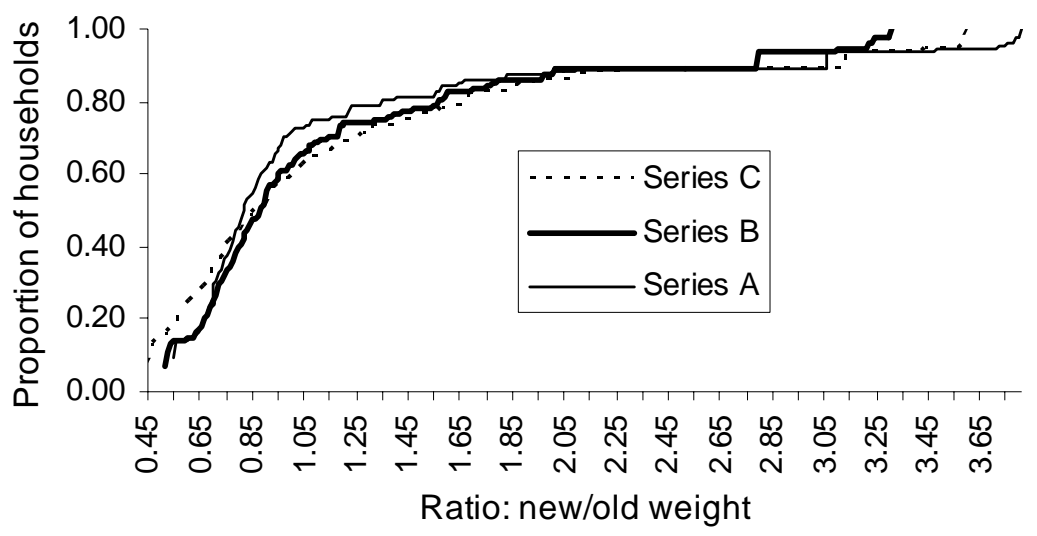

\footnotetext{
${ }^{13}$ Up to age 14 , only age can be observed in SIHC. Gender is not available for this group.
} 
As anticipated, the weights in this section deviate more from the ABS weights than the earlier revised weights (which had a range for the ratio of new to old weights of 0.68 to 1.87 ). The substantial changes in the age structure of the population require some age groups to be weighted up and others to be weighted down. The minimum range that could be imposed in the D-S approach increased to [0.51, 3.25] for the 2050 reweighting using the medium population projection (series B). The upper boundary seems relatively more affected by the difference in age structure, which can be explained by the relatively sharp increase that the older age group needs to make, compared with the smaller decrease of the other groups which is spread across a larger age range. Comparing the restrictions on the bounds that can be achieved in the different scenarios shows that the range is narrowest for the medium population scenario. This may be explained by the fact that although series $\mathrm{B}$ has a higher proportion of people over 50 than the young population, the proportion of people over 75 is lower. This means that this relatively small group of people over 75 needs to have a larger increase in their weights in series $\mathrm{A}$ and $\mathrm{C}$.

The effects on wage and salary income distributions of reweighting are shown in Figure 4, for the three population series, which shows for each income level the reweighted frequency minus the initial frequency. In each case there is little change in the proportion of persons on very high wages, but the proportion on medium wage and salary incomes, in particular, has decreased. This has mostly gone to an increase in the proportion of people who have no wage and salary income. This is not shown in Figure 4, but the differences at zero income for series A to C respectively are 13.17, 12.08 and 13.55. The income from wage and salary distribution is further from the 2001 distribution in series $\mathrm{A}$ and $\mathrm{C}$ compared with B. A possible explanation for this is that the younger population has a larger proportion of children whereas the older population has a larger proportion of potentially retired people. The medium-aged population, B, on the other hand, has the highest proportion in the working-age category, resulting in a larger proportion of the population on non-zero wage and salary income. 
Figure 4 Difference of frequency distribution of weekly wage and salary income using ABS weights versus new weights for projected population structure of 2050

ABS Series A

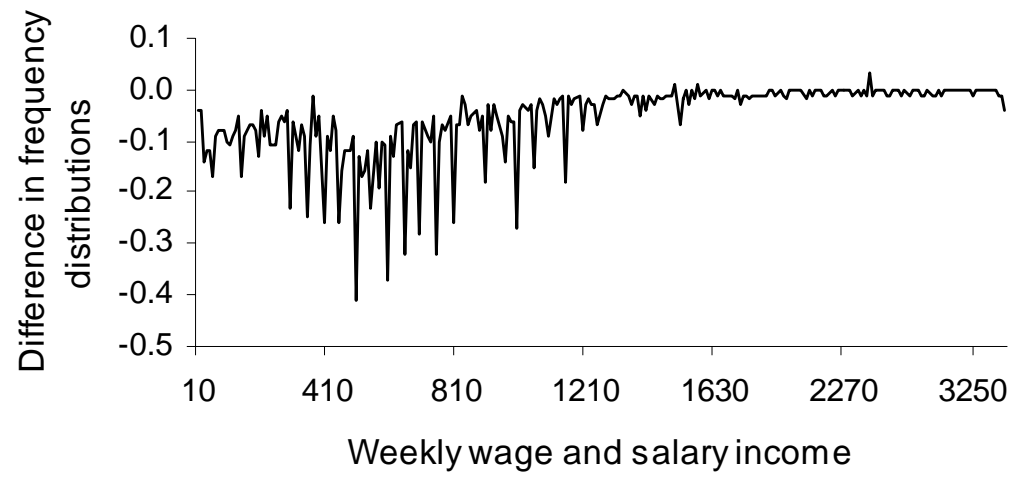

ABS: Series B

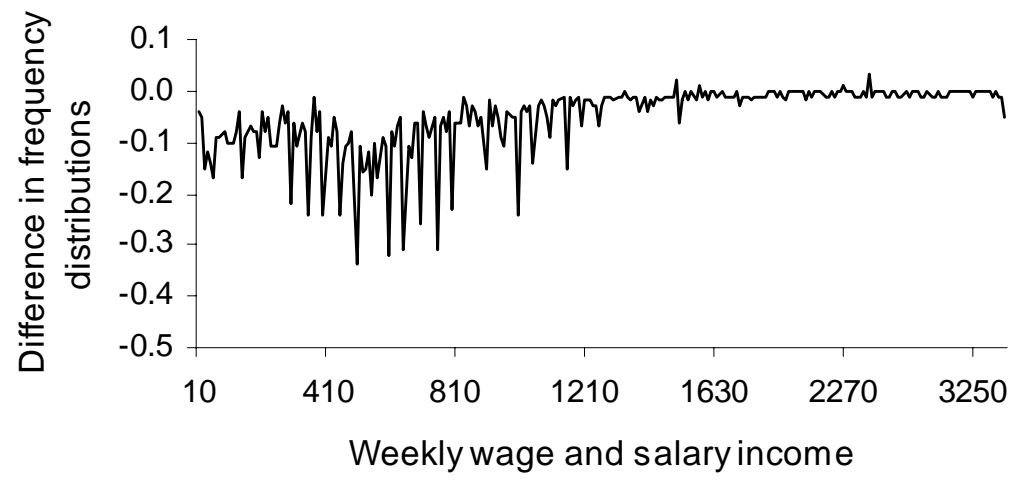

ABS: Series C

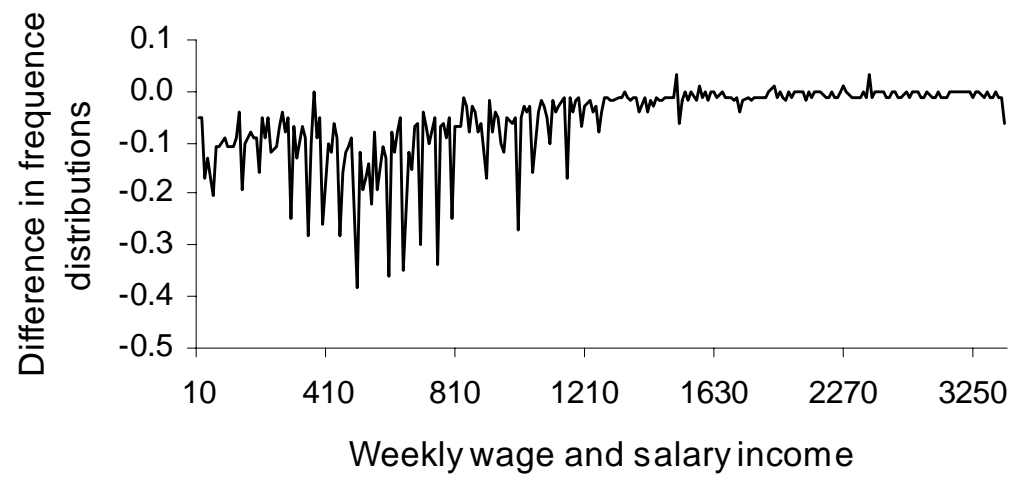

\subsection{Population Ageing, Taxes and Expenditure}

This section examines the effect of population ageing on government expenditure and revenue, if the changed demographic structure of the population were realised in 2001. 
Table 4 presents the results for the medium population projection (series B). As expected, a larger proportion of people pay income tax, as there are fewer children and dependent adolescents, but at a lower level given the lower income of retirees. This results in a decrease in the revenue from taxation. Similarly the Medicare levy decreases and rebates increase.

On the expenditure side, the number of people on pensions increases substantially, while the number of people on allowances and family payments decreases. The age pension sees the largest increase, in line with the ageing population and a smaller increase is observed for the disability pension, which also tends to be received by older individuals. When eligibility for the age pension is based on observed receipt in SIHC (to account for the lack of information on assets in SIHC), the expenditure on the age pension becomes smaller, as shown in the last two columns in Table 4. However, the relative increase in the expenditure due to population ageing, when comparing to the expenditure in 2001 based on observed eligibility for age pension (not presented in Table 4$)^{14}$, is similar to the relative increase in the middle two columns compared to the first two columns in Table 4. Of the allowances, only the mature age allowance and the partner allowance increase.

Table 5 presents the results for the two alternative population projection scenarios A and C. Comparing the change in net expenditure, series B is the least costly. In 2050, revenue is higher and expenditure is lower for B than for A and C, which is caused by the larger proportion of population B in the working age groups. Assuming similar employment rates as there were in 2000/01, a larger proportion of population B is therefore going to be self-sufficient without the need for government support.

\footnotetext{
${ }^{14}$ See Cai, Creedy and Kalb (2004) for these numbers in 2001.
} 
Table 4 Simulated impact of population ageing on revenue and expenditure

\begin{tabular}{|c|c|c|c|c|c|c|}
\hline & \multicolumn{2}{|c|}{$\begin{array}{l}\text { Simulation using ABS } \\
\text { weight }\end{array}$} & \multicolumn{4}{|c|}{$\begin{array}{l}\text { Simulation using weights derived from } \\
\text { projected medium population (B) in } 2050\end{array}$} \\
\hline & \multirow[b]{2}{*}{$\begin{array}{r}\text { Revenue or } \\
\text { expenditure } \\
(\$ \mathrm{~m})\end{array}$} & \multirow[b]{2}{*}{$\begin{array}{r}\text { Persons } \\
(1000)\end{array}$} & \multicolumn{2}{|c|}{$\begin{array}{l}\text { Using calculated age } \\
\text { pension eligibility }\end{array}$} & \multicolumn{2}{|c|}{$\begin{array}{l}\text { Using observed age } \\
\text { pension eligibility }\end{array}$} \\
\hline & & & $\begin{array}{r}\text { Revenue or } \\
\text { expenditure } \\
(\$ \mathrm{~m})\end{array}$ & $\begin{array}{r}\text { Persons } \\
(1000)\end{array}$ & $\begin{array}{r}\text { Revenue or } \\
\text { expenditure } \\
(\$ \mathrm{~m})\end{array}$ & $\begin{array}{r}\text { Persons } \\
(1000)\end{array}$ \\
\hline \multicolumn{7}{|l|}{ Government Revenue } \\
\hline Income Tax & $79,707.8$ & 12,103 & $71,294.3$ & 13,411 & $71,143.5$ & 13,286 \\
\hline Medicare Levy & $5,727.8$ & 7,762 & $5,102.2$ & 7,271 & $5,087.4$ & 7,223 \\
\hline Total Revenue & $85,435.6$ & & $76,396.5$ & & $76,230.9$ & \\
\hline \multicolumn{7}{|l|}{ Government Expenditure } \\
\hline Tax Rebates & $2,889.1$ & 6,294 & $4,515.7$ & 8,410 & $4,463.7$ & 8,287 \\
\hline FTP/FTB & $9,548.4$ & 1,935 & 6,198.6 & 1,277 & $6,198.6$ & 1,277 \\
\hline Allowances & $16,539.6$ & 2,657 & $14,222.8$ & 2,239 & $14,222.8$ & 2,239 \\
\hline Pensions & $26,437.0$ & 3,102 & $52,076.8$ & 6,127 & $50,410.0$ & 5,868 \\
\hline Pharm Allowance & 383.8 & 3,556 & 665.9 & 6,472 & 640.7 & 6,211 \\
\hline Rent Allowance & $2,033.5$ & 1,454 & $1,971.1$ & 1,597 & $1,925.8$ & 1,558 \\
\hline Total Expenditure & $57,831.5$ & & $79,651.0$ & & $77,861.5$ & \\
\hline Net Expenditure & $-27,604.1$ & & $3,254.5$ & & $1,630.6$ & \\
\hline \multicolumn{7}{|l|}{ Allowance } \\
\hline Parenting Payment (single) & $3,253.6$ & 389 & $2,259.3$ & 267 & $2,259.3$ & 267 \\
\hline Parenting Payment (couple) & $1,783.9$ & 285 & $1,196.7$ & 192 & $1,196.7$ & 192 \\
\hline Sickness Allowance & 181.7 & 21 & 176.3 & 20 & 176.3 & 20 \\
\hline Widow's Allowance & 4.9 & 1 & 2.5 & 0 & 2.5 & 0 \\
\hline AUSTUDY/ABSTUDY & 947.1 & 135 & 722.7 & 103 & 722.7 & 103 \\
\hline NewStart Allowance & $4,268.1$ & 660 & $3,811.2$ & 584 & $3,811.2$ & 584 \\
\hline Mature Age Allowance & 221.2 & 47 & 303.0 & 60 & 303.0 & 60 \\
\hline Youth Allowance & $2,475.7$ & 674 & $1,820.4$ & 491 & $1,820.4$ & 491 \\
\hline Special Benefit & $1,910.2$ & 232 & $1,992.5$ & 246 & $1,992.5$ & 246 \\
\hline Partner Allowance & $1,493.2$ & 215 & $1,938.3$ & 275 & $1,938.3$ & 275 \\
\hline Total Allowance Cost & $16,539.6$ & & $14,222.8$ & & $14,222.8$ & \\
\hline \multicolumn{7}{|l|}{ Pension } \\
\hline Age Pension & $15,865.0$ & 1,935 & $34,148.3$ & 4,171 & $32,733.9$ & 3,947 \\
\hline Dis.Support Pension & $5,133.8$ & 575 & $6,144.3$ & 682 & $6,144.3$ & 682 \\
\hline Wife’s Pension & 792.9 & 101 & $1,099.2$ & 139 & $1,082.4$ & 136 \\
\hline Widow B Pension & 398.2 & 41 & 311.7 & 32 & 311.7 & 32 \\
\hline Carer’s Payment & 274.1 & 33 & 371.9 & 44 & 371.9 & 44 \\
\hline Veteran Pension & $1,812.7$ & 233 & $5,327.5$ & 672 & $5,125.2$ & 644 \\
\hline Veterans Dis.Pension & $1,063.5$ & 101 & $2,357.4$ & 213 & $2,324.0$ & 208 \\
\hline War Widows Pension & $1,096.9$ & 83 & $2,316.6$ & 174 & $2,316.6$ & 174 \\
\hline Total Pension Cost & $26,437.0$ & & $52,076.8$ & & $50,410.0$ & \\
\hline \multicolumn{7}{|l|}{ Rebate } \\
\hline Beneficiary Rebate & 457.9 & 1,193 & 433.5 & 1,119 & 433.5 & 1,119 \\
\hline Pension Rebate & $2,388.3$ & 2,213 & $5,137.6$ & 4,781 & $5,168.8$ & 4,771 \\
\hline SP Pension Rebate & 256.1 & 349 & 177.7 & 243 & 177.7 & 243 \\
\hline Low Income Rebate & $1,250.6$ & 8,715 & $1,531.9$ & 10,608 & $1,533.7$ & 10,620 \\
\hline Dep Spouse Rebate & 423.3 & 416 & 481.5 & 512 & 576.8 & 569 \\
\hline Total Rebate Cost & $4,776.3$ & & $7,762.2$ & & $7,890.5$ & \\
\hline
\end{tabular}


Table 5 Simulated government revenue and costs using 2050 projections

\begin{tabular}{|c|c|c|c|c|c|c|}
\hline & \multirow{2}{*}{\multicolumn{2}{|c|}{$\begin{array}{l}\text { Simulation using } \\
\text { ABS weight }\end{array}$}} & \multicolumn{4}{|c|}{$\begin{array}{c}\text { Simulation using weights derived from } \\
\text { projected population structure B }\end{array}$} \\
\hline & & & \multicolumn{2}{|c|}{ Young population } & \multicolumn{2}{|c|}{ Old population } \\
\hline & $\begin{array}{r}\text { Revenue or } \\
\text { expenditure } \\
(\$ \mathrm{~m})\end{array}$ & $\begin{array}{r}\text { Persons } \\
(1000) \\
\end{array}$ & $\begin{array}{r}\text { Revenue or } \\
\text { expenditure } \\
(\$ \mathrm{~m})\end{array}$ & $\begin{array}{r}\text { Persons } \\
(1000) \\
\end{array}$ & $\begin{array}{r}\text { Revenue or } \\
\text { expenditure } \\
(\$ \mathrm{~m})\end{array}$ & $\begin{array}{r}\text { Persons } \\
(1000)\end{array}$ \\
\hline \multicolumn{7}{|l|}{ Government Revenue } \\
\hline Income Tax & $79,707.8$ & 12,103 & $68,629.0$ & 13,230 & $71,222.3$ & 13,774 \\
\hline Medicare Levy & $5,727.8$ & 7,762 & $4,889.2$ & 7,005 & $5,106.1$ & 7,331 \\
\hline Total Revenue & $85,435.6$ & & 73,518.2 & & $76,328.4$ & \\
\hline \multicolumn{7}{|c|}{ Government Expenditure } \\
\hline Tax Rebates & $2,889.1$ & 6,294 & $4,560.2$ & 8,416 & $4,814.7$ & 8,811 \\
\hline FTP/FTB & $9,548.4$ & 1,935 & $6,765.0$ & 1,365 & $5,309.0$ & 1,111 \\
\hline Allowances & $16,539.6$ & 2,657 & $14,004.8$ & 2,206 & $13,869.2$ & 2,176 \\
\hline Pensions & $26,437.0$ & 3,102 & $53,206.0$ & 6,233 & $56,644.3$ & 6,658 \\
\hline Pharm Allow & 383.8 & 3,556 & 683.0 & 6,592 & 715.4 & 6,972 \\
\hline Rent Allowance & $2,033.5$ & 1,454 & $2,029.2$ & 1,622 & $1,940.6$ & 1,620 \\
\hline Total Expenditure & $57,831.5$ & & $81,248.2$ & & $83,293.2$ & \\
\hline Net Expenditure & $-27,604.1$ & & $7,730.0$ & & $6,964.9$ & \\
\hline \multicolumn{7}{|l|}{ Allowance } \\
\hline $\begin{array}{l}\text { Parenting Payment } \\
\text { (single) }\end{array}$ & 3,253.6 & 389 & $2,466.9$ & 290 & $1,961.3$ & 233 \\
\hline $\begin{array}{l}\text { Parenting Payment } \\
\text { (couple) }\end{array}$ & $1,783.9$ & 285 & $1,274.7$ & 204 & $1,054.2$ & 168 \\
\hline Sickness Allowance & 181.7 & 21 & 158.9 & 18 & 185.5 & 21 \\
\hline Widow's Allowance & 4.9 & 1 & 2.6 & 0 & 2.2 & 0 \\
\hline AUSTUDY/ABSTUDY & 947.1 & 135 & 710.3 & 101 & 689.9 & 100 \\
\hline NewStart Allowance & $4,268.1$ & 660 & $3,631.0$ & 554 & $3,831.1$ & 586 \\
\hline Mature Age Allowance & 221.2 & 47 & 271.8 & 54 & 320.0 & 63 \\
\hline Youth Allowance & $2,475.7$ & 674 & $1,878.2$ & 507 & $1,697.2$ & 458 \\
\hline Special Benefit & $1,910.2$ & 232 & $1,879.2$ & 233 & $2,053.0$ & 254 \\
\hline Partner Allowance & $1,493.2$ & 215 & $1,731.0$ & 246 & $2,074.8$ & 293 \\
\hline Total Allowance Cost & $16,539.6$ & & $14,004.8$ & & $13,869.2$ & \\
\hline \multicolumn{7}{|l|}{ Pension } \\
\hline Age Pension & $15,865.0$ & 1,935 & $34,762.7$ & 4,224 & $37,243.1$ & 4,545 \\
\hline Dis.Support Pension & $5,133.8$ & 575 & $5,743.9$ & 636 & $6,510.2$ & 722 \\
\hline Wife's Pension & 792.9 & 101 & $1,032.2$ & 130 & $1,182.1$ & 149 \\
\hline Widow B Pension & 398.2 & 41 & 288.3 & 30 & 310.0 & 32 \\
\hline Carer's Payment & 274.1 & 33 & 359.3 & 43 & 399.8 & 47 \\
\hline Veteran Pension & $1,812.7$ & 233 & $6,037.6$ & 759 & $5,867.4$ & 739 \\
\hline Veterans Dis.Pension & $1,063.5$ & 101 & $2,565.7$ & 230 & $2,560.0$ & 231 \\
\hline War Widows Pension & $1,096.9$ & 83 & $2,416.2$ & 181 & $2,571.8$ & 193 \\
\hline Total Pension Cost & $26,437.0$ & & $53,206.0$ & & $56,644.3$ & \\
\hline \multicolumn{7}{|l|}{ Rebate } \\
\hline Beneficiary Rebate & 457.9 & 1,193 & 413.5 & 1,066 & 437.0 & 1,125 \\
\hline Pension Rebate & $2,388.3$ & 2,213 & $5,310.4$ & 4,913 & $5,605.0$ & 5,211 \\
\hline SP Pension Rebate & 256.1 & 349 & 193.5 & 264 & 154.6 & 211 \\
\hline Low Income Rebate & $1,250.6$ & 8,715 & $1,533.0$ & 10,610 & $1,586.9$ & 10,983 \\
\hline Dep Spouse Rebate & 423.3 & 416 & 430.7 & 465 & 518.3 & 552 \\
\hline Total Rebate Cost & $4,776.3$ & & $7,881.1$ & & $8,301.8$ & \\
\hline
\end{tabular}




\section{Policy Simulation With Aged Population Structure}

Population ageing is of course likely to lead to a different response to policy changes. Hence this section examines a policy change using the reweighted population rather than the 2001 weights. The policy change involves a reduction to 30 per cent in all benefit taper rates over 30 per cent. Results are reported for population series B and Table 6 compares the labour supply response to this policy change for the current and the updated population. The first row in the two panels in Table 6 presents the percentage of workers in the pre-reform situation.

Table 6 Simulated impacts on labour supply of population ageing

\begin{tabular}{lccccc}
\hline & $\begin{array}{c}\text { Married } \\
\text { men }\end{array}$ & $\begin{array}{c}\text { Married } \\
\text { women }\end{array}$ & $\begin{array}{c}\text { Single } \\
\text { men }\end{array}$ & $\begin{array}{c}\text { Single } \\
\text { women }\end{array}$ & $\begin{array}{c}\text { Single } \\
\text { parents }\end{array}$ \\
\hline \multicolumn{5}{c}{ ABS weights } \\
all workers (\%base) $)^{(1)}$ & 71.67 & 55.42 & 62.04 & 50.06 & 49.62 \\
worker, hrs known(\%base) & 58.08 & 48.61 & 54.94 & 47.09 & 42.64 \\
worker, hrs known(\%post) & 58.68 & 48.02 & 55.57 & 47.68 & 45.81 \\
non-work-->work (\%) & 1.24 & 0.62 & 0.76 & 0.66 & 3.38 \\
work-->non-work (\%) & 0.64 & 1.22 & 0.13 & 0.06 & 0.21 \\
workers working more & 0.25 & 0.23 & 0.00 & 0.04 & 1.00 \\
workers working less & 1.04 & 0.69 & 0.83 & 2.01 & 1.35 \\
average hours change & 0.09 & -0.35 & 0.08 & -0.14 & 1.03 \\
\hline \multicolumn{1}{c}{ Projected population structure of 2050 Series B } & \\
all workers (\%base) (1) & 54.35 & 42.20 & 53.77 & 38.15 & 48.93 \\
worker, hrs known(\%base) & 42.60 & 36.15 & 46.31 & 35.73 & 41.81 \\
worker, hrs known(\%post) & 43.27 & 35.82 & 46.93 & 36.16 & 44.97 \\
non-work-->work (\%) & 1.15 & 0.55 & 0.74 & 0.48 & 3.39 \\
work-->non-work (\%) & 0.48 & 0.88 & 0.11 & 0.05 & 0.23 \\
workers working more & 0.18 & 0.17 & 0.00 & 0.03 & 1.00 \\
workers working less & 0.73 & 0.53 & 0.70 & 1.57 & 1.40 \\
average hours change & 0.16 & -0.24 & 0.10 & -0.13 & 1.02 \\
\hline Nere (1): The
\end{tabular}

Note (1): The group in this first row includes the self-employed for whom no hours of work are observed. Only the effect for wage and salary earners (for whom hours are known) is simulated in MITTS.

Comparing the two sets of results, lower participation rates for all groups except sole parents is evident in the series B age structure. The labour supply responses are similar for both sections. For sole parents the change is minimal. This group may have become smaller, but the age composition of this group is unlikely to have shifted towards the 60 and over group to a large extent. Similarly, there is little change in the effect for single persons. The negative effect for single and married women is slightly smaller and the positive effect for single and married men is slightly larger. For married men and women, the proportion moving to non-work or working fewer hours after the 
policy change has decreased in the aged population, possibly because they are already at a lower level of participation in the updated population. This causes the slightly more positive labour supply response for men and the slightly less negative labour supply response for women.

Finally, the effects of the policy change on government expenditure and revenue are shown in Table 7 which compares results with those obtained using the original ABS weights. Although total expenditure on couples is projected to increase as a result of population ageing, it is mostly through pensions. People on age and disability pensions are assumed to be non-responsive to financial incentives and most of them are not working, so they do not benefit from the taper rate reduction. Therefore, a smaller proportion of the 2050 population is expected to benefit from the policy change. As a result the cost of the policy change is lower for couples in the 2050 projection compared with 2000-2001. For single men and women the cost is similar to before, although the total expenditure increases just as for couples. For sole parents both the total expenditure and the cost of the policy change is lower with the projected 2050 population structure. This is the result of a reduced number of sole parents as a proportion of the total population when the revised weights are used ${ }^{15}$.

Table 7 Simulated tax and transfer costs allowing for labour supply responses

\begin{tabular}{|c|c|c|c|c|}
\hline & \multicolumn{2}{|c|}{ ABS weights } & \multicolumn{2}{|c|}{2050 Series B } \\
\hline & $\begin{array}{l}\text { Pre-reform } \\
\text { Value }(\$ \mathrm{~m})\end{array}$ & $\begin{array}{l}\text { Change } \\
\text { r reform } \\
\text { lue }(\$ \mathrm{~m})\end{array}$ & $\begin{array}{l}\text { Pre-reform } \\
\text { Value }(\$ \mathrm{~m})\end{array}$ & $\begin{array}{l}\text { Change } \\
\text { er reform } \\
\text { lue }(\$ \mathrm{~m})\end{array}$ \\
\hline \multicolumn{5}{|l|}{ Government Revenue } \\
\hline Income Tax & $57,474.3$ & 356.9 & $48,841.7$ & 548.80 \\
\hline Medicare & $4,023.6$ & 96.4 & $3,403.8$ & 94.8 \\
\hline Total Revenue & $61,497.9$ & 453.2 & $52,245.5$ & 643.6 \\
\hline \multicolumn{5}{|c|}{ Government Expenditure } \\
\hline Tax Rebates & $1,537.6$ & -152.6 & $2,540.2$ & -214.9 \\
\hline FTP/FTB & $6,006.6$ & 893.0 & $3,838.7$ & 555.6 \\
\hline Allowances & $6,065.6$ & $4,697.7$ & $5,627.7$ & $4,144.7$ \\
\hline Pensions & $13,641.1$ & 465.0 & $28,705.7$ & 951.6 \\
\hline Pharm Allowance & 134.0 & 8.0 & 276.7 & 13.3 \\
\hline Rent Allowance & 647.3 & 231.2 & 570.7 & 192.6 \\
\hline Total Expenditure & $28,032.1$ & $6,142.2$ & $41,559.7$ & $5,642.9$ \\
\hline Net Expenditure & $-33,465.9$ & $5,688.9$ & $-10,685.8$ & $4,999.3$ \\
\hline
\end{tabular}

\footnotetext{
${ }^{15}$ The weighted number of sole parents is 589,287 using ABS weights and 411,727 using weights derived from the projected 2050 population structure.
} 


\begin{tabular}{|c|c|c|c|c|}
\hline \multirow{2}{*}{$\begin{array}{l}\text { Single Men } \\
\end{array}$} & \multicolumn{2}{|c|}{ ABS weights } & \multicolumn{2}{|c|}{2050 Series B } \\
\hline & \multicolumn{2}{|c|}{$\begin{array}{l}\text { Change } \\
\text { Pre-reform after reform } \\
\text { Value }(\$ \mathrm{~m}) \text { Value }(\$ \mathrm{~m})\end{array}$} & \multicolumn{2}{|c|}{$\begin{array}{l}\text { Change } \\
\text { Pre-reform after reform } \\
\text { Value }(\$ \mathrm{~m}) \text { Value }(\$ \mathrm{~m})\end{array}$} \\
\hline \multicolumn{5}{|l|}{ Government Revenue } \\
\hline Income Tax & $12,839.4$ & 288.4 & $12,882.7$ & 316.8 \\
\hline Medicare & $1,019.2$ & 27.3 & $1,008.3$ & 28.8 \\
\hline Total Revenue & $13,858.6$ & 315.7 & $13,891.0$ & 345.6 \\
\hline \multicolumn{5}{|c|}{ Government Expenditure } \\
\hline Tax Rebates & 414.7 & -19.4 & 702.5 & -29.1 \\
\hline Allowances & $4,298.9$ & $1,051.5$ & 3,993.8 & 980.4 \\
\hline Pensions & $4,085.4$ & 94.4 & $8,230.0$ & 199.4 \\
\hline Pharm Allowance & 65.8 & 1.8 & 131.0 & 2.9 \\
\hline Rent Allowance & 465.0 & 397.3 & 578.8 & 371.2 \\
\hline Total Expenditure & $9,329.8$ & $1,525.6$ & $13,636.1$ & $1,524.8$ \\
\hline Net Expenditure & $-4,528.8$ & $1,209.9$ & -254.9 & $1,179.2$ \\
\hline \multicolumn{5}{|l|}{ Single women } \\
\hline \multicolumn{5}{|l|}{ Government Revenue } \\
\hline Income Tax & $7,510.5$ & 131.4 & $8,279.0$ & 145.8 \\
\hline Medicare & 592.9 & 14.9 & 629.3 & 15.4 \\
\hline Total Revenue & $8,103.4$ & 146.2 & $8,908.4$ & 161.1 \\
\hline \multicolumn{5}{|c|}{ Government Expenditure } \\
\hline Tax Rebates & 650.1 & -17.2 & $1,071.0$ & -24.6 \\
\hline Allowances & 2,633.9 & 956.8 & $2,120.2$ & 869.5 \\
\hline Pensions & $8,529.4$ & 105.7 & $15,030.6$ & 214.5 \\
\hline Pharm Allowance & 124.8 & 1.9 & 217.4 & 2.6 \\
\hline Rent Allowance & 344.1 & 280.7 & 424.3 & 236.6 \\
\hline Total Expenditure & $12,282.3$ & $1,327.9$ & $18,863.4$ & $1,298.7$ \\
\hline Net Expenditure & $4,178.9$ & $1,181.7$ & $9,955.0$ & $1,137.5$ \\
\hline \multicolumn{5}{|l|}{ Sole parents } \\
\hline \multicolumn{5}{|l|}{ Government Revenue } \\
\hline Income Tax & $1,961.8$ & 120.3 & $1,337.2$ & 79.9 \\
\hline Medicare & 93.5 & 11.0 & 63.2 & 7.2 \\
\hline Total Revenue & $2,055.3$ & 131.3 & $1,400.4$ & 87.1 \\
\hline \multicolumn{5}{|c|}{ Government Expenditure } \\
\hline Tax Rebates & 291.8 & -19.7 & 205.2 & -13.7 \\
\hline FTP/FTB & $3,508.7$ & 82.4 & $2,338.1$ & 49.6 \\
\hline Allowances & $3,632.6$ & 219.0 & $2,556.7$ & 144.0 \\
\hline Pensions & 210.3 & -0.1 & 159.8 & 0.5 \\
\hline Pharm Allowance & 59.3 & 6.4 & 41.0 & 3.9 \\
\hline Rent Allowance & 575.0 & 6.4 & 396.0 & 4.4 \\
\hline Total Expenditure & $8,277.6$ & 294.4 & $5,696.8$ & 188.6 \\
\hline Net Expenditure & $6,222.3$ & 163.1 & $4,296.4$ & 101.5 \\
\hline
\end{tabular}




\section{Conclusions}

This paper has investigated the use of sample reweighting in MITTS, a behavioural tax microsimulation model, to examine the implications of population ageing for government revenue and expenditure in Australia.

First, a calibration approach to sample reweighting was described. This produces new weights which achieve specified population totals for selected variables, subject to the constraint that there are minimal adjustments to the weights. Second, the performance of the ABS weights provided with the 2001 SIHC, for obtaining aggregate government expenditure and revenue estimates and numbers of people receiving various benefits, was examined. This was needed because population aggregates for variables not used in official calibrations may deviate from population values obtained from other data sources, such as official administrative data on tax revenue and expenditures. It was found that reweighting does not improve the simulation outcomes, so the original ABS weights were retained for 2001.

Third, the implications of changes in the age distribution of the population were examined, based on ABS population projections to 2050. A 'pure' change in the age distribution was examined by keeping the aggregate population size fixed and changing only the relative frequencies in different age groups. This example of an ageing population shows that the cost of social security is expected to increase and the revenue from income tax is expected to decrease. It is suggested that this type of exercise provides an insight into the implications of changes in the population on government income tax revenue and social security expenditure, indicating likely pressures for policy changes.

Finally, the effects of a policy change to benefit taper rates in Australia were compared for 2001 and 2050 population weights. Assuming that labour force participation rates have not changed between 2001 and 2050, this shows that the cost of such a policy is expected to cost slightly less in absolute terms and considerably less in relative terms (as a proportion of the expenditure before the policy change) for the 2050 population. The larger proportion of the population out of the labour force means that fewer people benefit from the taper rate reduction. As a result a taper rate reduction is expected to be less costly in the older population.

Sample reweighting could of course be used to examine other types of change, including for example changes in unemployment rates. It is suggested that the kind of 
reweighting approach discussed here provides much scope for providing insights into the implications of changes to the population composition.

\section{References}

Alvarado, J. and Creedy, J. (1998) Population Ageing, Migration and Social Expenditure. Cheltenham: Edward Elgar.

Australian Bureau of Statistics (ABS) (2002) 2001 Census Community Profile Series: Basic Community Profile, ABS Cat No. 2001.0.

(2003) Population Projection Australia 2002-2101, ABS Cat No. 3222.0.

Cai, L., Creedy, J. and Kalb, G. (2004) "Reweighting the Survey of Income and Housing Costs for Tax Microsimulation Modelling”, Final report prepared for the Department of Family and Community Services.

Creedy, J., Duncan, A.S., Harris, M., and Scutella, R. (2002) Microsimulation Modelling of Taxation and The Labour Market: The Melbourne Institute Tax and Transfer Simulator. Cheltenham: Edward Elgar.

Department of Family and Community Services (FaCS) (2001) Department of Family and Community Services Annual Report 2000-01, Canberra.

(2003) Income Support Customers: A Statistical Overview 2001, Occasional Paper No. 7.

Deville, J.-F. and Särndal, C.-E. (1992) Calibration estimators in survey sampling. Journal of the American Statistical Association, 87, pp. 376-382.

Folsom, R.E. Jr. and Singh, A.C. (2000) The generalized exponential model for sampling weight calibration for extreme values, non-response and poststratification. Proceedings of the Survey Research Methods Section: American Statistical

Association. http://www.amstat.org/sections/srms/proceedings/papers/2000_099.pdf.

Singh, A.C. and Mohl, C.A. (1996) Understanding calibration estimators in survey sampling. Survey Methodology, 22, pp. 107-115.

Vanderhoeft, C. (2001) Generalised calibration at Statistics Belgium. Statistics Belgium Working Paper, no. 3. 


\section{Appendix A. An Iterative Solution Procedure}

This appendix describes an iterative procedure for solving the nonlinear equations required for minimising the distance between new and old sample weights. Writing $t_{x}-\hat{t}_{x \mid s}=a$, the equations in (10) can be written as:

$$
f_{i}(\lambda)=a_{i}-\sum_{k=1}^{K} s_{k} x_{k, i}\left\{g^{-1}\left(x_{k}^{\prime} \lambda\right)-1\right\}=0
$$

for $i=1, \ldots, J$. The roots of this equation can be obtained using Newton's method, which involves the following iterative sequence, where $\lambda^{[I]}$ denotes the value of $\lambda$ in the $I^{\text {th }}$ iteration: ${ }^{16}$

$$
\lambda^{[I+1]}=\lambda^{[I]}-\left[\frac{\partial f_{i}(\lambda)}{\partial \lambda_{\ell}}\right]_{\lambda^{[I]}}^{-1}[f(\lambda)]_{\lambda^{[I]}}
$$

The Hessian matrix $\left[\partial f_{i}(\lambda) / \partial \lambda_{\ell}\right]$ and the vector $f(\lambda)$ on the right hand side of (14) are evaluated using $\lambda^{[I]}$. The elements $\partial f_{i}(\lambda) / \partial \lambda_{\ell}$ are given by:

$$
\frac{\partial f_{i}(\lambda)}{\partial \lambda_{\ell}}=-\sum_{k=1}^{K} s_{k} x_{k, i} \frac{\partial g^{-1}\left(x_{k}^{\prime} \lambda\right)}{\partial \lambda_{\ell}}
$$

which can be written as:

$$
\frac{\partial f_{i}(\lambda)}{\partial \lambda_{\ell}}=-\sum_{k=1}^{K} s_{k} x_{k, i} x_{k, \ell} \frac{d g^{-1}\left(x_{k}^{\prime} \lambda\right)}{d\left(x_{k}^{\prime} \lambda\right)}
$$

Starting from arbitrary initial values, the matrix equation in (14) is used repeatedly to adjust the values until convergence is reached, where possible.

As mentioned above, the application of the approach requires that it is limited to distance functions for which the form of the inverse function, $g^{-1}(u)$, can be obtained explicitly, given the specification for $G(w, s)$. Hence, the Hessian can easily be evaluated at each step using an explicit expression for $d g^{-1}\left(x_{k}^{\prime} \lambda\right) / d\left(x_{k}^{\prime} \lambda\right)$. As these expressions avoid the need for the numerical evaluation of $g^{-1}\left(x_{k}^{\prime} \lambda\right)$ and

\footnotetext{
${ }^{16}$ The approach described here differs somewhat from other routines described in the literature, for example in Singh and Mohl (1996) and Vanderhoeft (2001). However, it provides extremely rapid convergence.
} 
$d g^{-1}\left(x_{k}^{\prime} \lambda\right) / d\left(x_{k}^{\prime} \lambda\right)$ for each individual at each step, the calculation of the new weights can be expected to be relatively quick, even for large samples. ${ }^{17}$ However, a solution does not necessarily exist, depending on the distance function used and the adjustment required to the vector $t_{x}-\hat{t}_{x \mid s}$.

The derivative required in the computation of the Hessian is for the D-S distance function is:

$$
\frac{d g^{-1}(u)}{d u}=g^{-1}(u)\left\{r_{U}-g^{-1}(u)\right\} \frac{\left(1-r_{L}\right) \alpha \exp \alpha u}{\left(r_{U}-1\right)+\left(1-r_{L}\right) \exp \alpha u}
$$

Since $g^{-1}(u)$ solves for $w / s$, equation (11) above can be rearranged, by collecting terms in $\exp \alpha u$, to give:

$$
\frac{\frac{w}{s}-r_{L}}{1-r_{L}}=\frac{r_{U}-\frac{w}{s}}{r_{U}-1} \exp \alpha u
$$

so that the gradient of the distance function is:

$$
g\left(\frac{w}{s}\right)=u=\frac{1}{\alpha}\left[\log \left(\frac{\frac{w}{s}-r_{L}}{1-r_{L}}\right)-\log \left(\frac{r_{U}-\frac{w}{s}}{r_{U}-1}\right)\right]
$$

This method has been found to provide rapid convergence.

\footnotetext{
${ }^{17}$ Using numerical methods to solve for each $g^{-1}(u)$ and $d g^{-1}(u) / d u$, for $u=x_{k}^{\prime} \lambda$, for every individual in each iteration, would increase the computational burden substantially.
} 


\section{Appendix B. Calibration Conditions For 2001}

Table 8 Population age distribution

\begin{tabular}{|c|c|c|c|}
\hline & $\begin{array}{l}\text { Required total } \\
\text { from Census } \\
2001^{(1)}\end{array}$ & $\begin{array}{c}\text { Estimated } \\
\text { total from } \\
\text { SIHC using } \\
\text { ABS weights } \\
\end{array}$ & Difference \\
\hline \multicolumn{4}{|c|}{ Population aged under $15^{(2)}$} \\
\hline $0-4$ & $1,243,969$ & $1,214,517$ & 29,452 \\
\hline $5-9$ & $1,331,926$ & $1,253,801$ & 78,125 \\
\hline $10-14$ & $1,336,580$ & $1,765,168$ & $-428,588$ \\
\hline \multicolumn{4}{|l|}{ Males } \\
\hline $15-19$ & 677,513 & 713,250 & $-35,737$ \\
\hline $20-24$ & 629,319 & 617,182 & 12,137 \\
\hline $25-29$ & 654,456 & 715,695 & $-61,239$ \\
\hline $30-34$ & 688,049 & 719,950 & $-31,901$ \\
\hline $35-39$ & 703,544 & 729,525 & $-25,981$ \\
\hline $40-44$ & 705,817 & 720,095 & $-14,278$ \\
\hline $45-49$ & 651,987 & 673,475 & $-21,488$ \\
\hline $50-54$ & 624,315 & 628,445 & $-4,130$ \\
\hline $55-59$ & 490,155 & 468,993 & 21,162 \\
\hline $60-64$ & 394,631 & 414,462 & $-19,831$ \\
\hline $65-69$ & 322,901 & 302,613 & 20,288 \\
\hline $70-74$ & 292,636 & 280,859 & 11,777 \\
\hline 75 and over & 427,221 & 404,355 & 22,866 \\
\hline \multicolumn{4}{|l|}{ Females } \\
\hline $15-19$ & 647,751 & 668,439 & $-20,688$ \\
\hline $20-24$ & 611,763 & 607,638 & 4,125 \\
\hline $25-29$ & 664,501 & 696,427 & $-31,926$ \\
\hline $30-34$ & 716,182 & 748,909 & $-32,727$ \\
\hline $35-39$ & 728,089 & 676,943 & 51,146 \\
\hline $40-44$ & 730,838 & 789,864 & $-59,026$ \\
\hline $45-49$ & 667,860 & 646,603 & 21,257 \\
\hline $50-54$ & 624,170 & 647,963 & $-23,793$ \\
\hline $55-59$ & 480,580 & 485,004 & $-4,424$ \\
\hline $60-64$ & 394,376 & 385,841 & 8,535 \\
\hline $65-69$ & 337,686 & 333,367 & 4,319 \\
\hline $70-74$ & 326,947 & 306,560 & 20,387 \\
\hline 75 and over & 663,487 & 546,531 & 116,956 \\
\hline Total & $18,769,249$ & $19,162,474$ & $-393,225$ \\
\hline
\end{tabular}

(1) Source: ABS (2002).

(2) The number of children variables in SIHC for the different age categories is mostly censored at 2. Therefore, the exact number of children in the different age categories cannot be calculated using information from the SIHC. In this table, we treated the censored number as the actual number, which is unlikely to be far from the actual value given the available age categories in the SIHC (that is, 0-2, 3-4, 59 , and 10-14 years of age). 
Table 9 Family composition

\begin{tabular}{lrrr}
\hline & $\begin{array}{r}\text { Required total } \\
\text { from Census } \\
2001^{(1)}\end{array}$ & $\begin{array}{r}\text { Estimated } \\
\text { total from } \\
\text { SIHC using } \\
\text { ABS weights }\end{array}$ & Difference \\
\hline $\begin{array}{l}\text { Couples without children } \\
\text { Couples with dependent children } \\
\text { only }\end{array}$ & $1,764,167$ & $1,886,483$ & $-122,316$ \\
$\begin{array}{c}\text { Couples with dependent and non- } \\
\text { dependent children }\end{array}$ & $1,661,963$ & $1,767,752$ & $-105,789$ \\
$\begin{array}{c}\text { Couples with non-dependent } \\
\text { children only }\end{array}$ & 242,159 & 285,577 & $-43,418$ \\
$\begin{array}{c}\text { Sole parents with dependent } \\
\text { children only }\end{array}$ & 417,043 & 459,372 & $-42,329$ \\
$\begin{array}{c}\text { Sole parents with dependent and } \\
\text { non-dependent children }\end{array}$ & 465,932 & 530,460 & $-64,528$ \\
$\begin{array}{c}\text { Sole parents with non-dependent } \\
\text { children only }\end{array}$ & 64,037 & 58,827 & 5,210 \\
\hline (1) Source: ABS (2002). & 232,663 & 250,421 & $-17,758$ \\
\hline
\end{tabular}

Table 10 Number of unemployed people

\begin{tabular}{lrrr}
\hline & $\begin{array}{r}\text { Required total } \\
\text { from Census } \\
2001^{(1)}\end{array}$ & $\begin{array}{r}\text { Estimated } \\
\text { total from } \\
\text { SIHC using } \\
\text { ABS weights }\end{array}$ & Difference \\
\hline Males & & & \\
15-19 years & 59,493 & 66,202 & $-6,709$ \\
20-24 years & 67,585 & 53,863 & 13,722 \\
25-34 years & 93,416 & 84,334 & 9,082 \\
35-44 years & 74,300 & 80,405 & $-6,105$ \\
45-54 years & 59,110 & 48,071 & 11,039 \\
55-64 years & 37,011 & 19,851 & 17,160 \\
\hline Females & & & \\
15-19 years & 50,921 & 55,461 & $-4,540$ \\
20-24 years & 45,704 & 36,408 & 9,296 \\
25-34 years & 61,263 & 54,502 & 6,761 \\
35-44 years & 56,553 & 60,112 & $-3,559$ \\
45-54 years & 38,463 & 43,212 & $-4,749$ \\
55-64 years & 12,319 & 16,831 & $-4,512$ \\
\hline Total & 656,138 & 619,252 & 36,886 \\
\hline
\end{tabular}

(1) Source: ABS (2002). 
Table 11 Number of income support recipients

\begin{tabular}{|c|c|c|c|}
\hline & $\begin{array}{l}\text { Required total } \\
\text { from } \mathrm{FaCS}^{(1)}\end{array}$ & $\begin{array}{r}\text { Estimated } \\
\text { total from } \\
\text { SIHC using } \\
\text { ABS weights } \\
\end{array}$ & Difference \\
\hline \multicolumn{4}{|l|}{ A. DSP } \\
\hline \multicolumn{4}{|l|}{ Couples } \\
\hline Males with dependents & 172,666 & 183,435 & $-10,769$ \\
\hline Females with dependents & 68,295 & 96,924 & $-28,629$ \\
\hline \multicolumn{4}{|l|}{ Singles } \\
\hline Males with dependents & 219,688 & 175,091 & 44,597 \\
\hline Females with dependents & 163,277 & 129,364 & 33,913 \\
\hline \multicolumn{4}{|c|}{ B. Parenting payments (single \& couple) } \\
\hline \multicolumn{4}{|l|}{ Males } \\
\hline Under 39 & 29,634 & 28,824 & 810 \\
\hline $40-49$ & 18,641 & 14,647 & 3,994 \\
\hline 50 and over & 5,349 & 4,700 & 649 \\
\hline \multicolumn{4}{|l|}{ Females } \\
\hline Under 29 & 180,100 & 196,069 & $-15,969$ \\
\hline $30-39$ & 250,438 & 298,710 & $-48,272$ \\
\hline $40-49$ & 137,478 & 182,098 & $-44,620$ \\
\hline 50 and over & 17,695 & 16,195 & 1,500 \\
\hline \multicolumn{4}{|c|}{ C. Wife pension, carers payment and widow allowance } \\
\hline Under 39 & 16,667 & 13,291 & 3,376 \\
\hline $40-49$ & 30,806 & 31,408 & -602 \\
\hline $50-59$ & 91,354 & 107,956 & $-16,602$ \\
\hline 60 and over & 32,480 & 31,083 & 1,397 \\
\hline
\end{tabular}

(1) Source: FaCS (2003). 